\title{
SOBRE O CAMPO LEXICAL DO LAZER: RESENHA DO DICIONÁRIO CRÍTICO DO LAZER.
}

\section{ABOUT THE LEXICAL FIELD OF THE LEISURE: SUMMARY \\ OF THE CRITICAL DICTIONARY OF THE LEISURE.}

Dr. Giuliano Gomes de Assis Pimentel

Faculdade de Educação Física/UNICAMP.

A necessidade de nomear e explicar a vida em sua totalidade é constituinte da própria condição humana em seu processo civilizatório. Definir, conceituar, nomear, descrever e explicar funcionam como uma cristalização do pensamento, pois tentam garantir, mesmo que provisoriamente, uma estabilidade que facilite a comunicação.

Esse 'congelamento' pelo conceito está sujeito à ação humana e, por isso, passível de ser mudado a cada paradigma quebrado. Mesmo considerada a provisoriedade tanto daquilo que significa quanto do que é significado, os campos de investigação, por conta de estabelecer sua tradição e um arcabouço consensual mínimo, acumulam historicamente discussão sobre determinadas categorias e conceitos pertinentes ao diálogo eficaz entre seus pares.

E foi no sentido de reunir, com a densidade necessária, alguns dos vocábulos mais utilizados no campo do lazer que Dicionário crítico do lazer traz fundamentação para a "reflexão crítica" de 50 verbetes pertinentes aos estudos do lazer. Para tanto, foram reunidos 38 autores e autores, os quais são provenientes de 10 diferentes formações representando, assim, a própria natureza multidisciplinar das pesquisas e intervenções no lazer.

A organizadora do Dicionário, autora de outras publicações sobre recreação e lazer, é também editora da revista Licere, periódico especializado nos estudos multidisciplinares sobre o lazer. Outra referência importante para legitimar a obra é a chancela do Centro de Estudos de Lazer e Recreação (CELAR/UFMG), tradicional grupo de pesquisas em atividade no país.

Além de necessário para consultas terminológicas por parte de estudiosos e neófitos desse campo, a obra possui valor histórico e heurístico, ao condensar em verbetes 
décadas de pesquisas e ensaios sobre lazer. É importante destacar que o trabalho constitui contribuição original trazendo tanto palavras quanto significados novos em relação às obras já publicadas no Brasil seja na Educação Física (FANALI, 1981; BARBANTI, 2002) seja no Turismo (PELLEGRINI FILHO, 2000; BRAGA, 2003) ou ainda nas Ciências Humanas e Sociais (OUTHWATTE; BOTTOMORE, 1996; THINÉS; LEMPEREUR, [197-]. Essas publicações eram, até o momento, as fontes mais próximas para se pesquisar verbetes pertinentes ao lazer, mas careciam ora de abrangência ora de especificidade. ${ }^{1}$

Por isso, e dado o amadurecimento do objeto lazer no meio acadêmico, premente se fazia a reunião de verbetes numa só obra. Para ilustrar alguns dos vocábulos eleitos pelo Dicionário crítico do lazer, podem ser encontrados: a)conceitos utilizados em diferentes campos ("trabalho"; "tempo livre"; "indústria cultural”; "cidadania"; "consumo"; "mídia"; "meio ambiente"; "políticas públicas"; "qualidade de vida"; "terceiro setor"; "gênero"), b)conteúdos culturais do lazer ("cinema"; "televisão"; "festa"; "esporte"; "internet"), e c)nichos de atuação profissional ("acampamento"; "colônia de férias", "parques"; "hotéis de lazer"; "rua de lazer"). Por fim, importante se faz destacar que a própria relação lazer-educação é tratada em um verbete que problematiza, numa leitura histórica, as perspectivas com que essa relação é estabelecida.

Boa parte dos vocábulos está estruturada de forma a fornecer definição do termo, etimologia, desenvolvimento histórico, embates teóricos, tipologias, bibliografia sugerida para consulta e autor do vocábulo. Antes, porém, de fazer uso desse material, leitores e leitoras precisam estar atentos a determinadas particularidades da obra. Por rigor da definição, Dicionário Crítico do Lazer pode parecer pouco específico do lazer, nem sempre crítico e muito menos um dicionário.

\footnotetext{
${ }^{1}$ Posteriormente ao lançamento da obra em análise foi publicado outro dicionário com teor crítico, o qual traz conteúdos ligados ao lazer ("atividades lúdicas", "tempo livre", "folclore", "lazer", "recreação" entre outros) em sua relação com a educação física. Cf. González, Fensterseifer (2005).
} 
Do latim dictionariu, dicionários científicos tendem a ser entendidos como a reunião de vocábulos cujos termos são próprios de uma área. A obra analisada contempla essa perspectiva, mas pode desapontar pela carência de vocábulos novos ou mesmo tradicionais. É estranho, por exemplo, que “jogo”, um vocábulo com especificidade semântica, não esteja contemplado. Portanto, a perspectiva desse dicionário parece ser a tentativa de aprofundar ao invés de tentar esgotar, mais superficialmente, a pluralidade de termos próprios ou fundamentais à compreensão do lazer.

Do ponto de vista da seleção dos verbetes, o dicionário não torna explícito seu vínculo a algum sistema 'crítico' mais geral (o Materialismo Histórico Dialético, por exemplo). Em acréscimo, epistemologicamente se pode dizer que noções, conceitos e categorias ${ }^{2}$ estão presentes indiscriminadamente no dicionário, da mesma forma que este abriga desde leituras marxistas (em "ócio" e "trabalho", por exemplo) até aquelas mais ligadas ao mercado ("eventos"; "shopping center"; "marketing", entre outras).

Neste sentido, poderia se questionar qual é a criticidade almejada pela obra, visto que esta não torna evidente um critério? Quanto ao adjetivo crítico, os autores da obra o adotam na perspectiva já sublinhada anteriormente: promover um juízo aprofundado. Os termos não são simplesmente definidos (aliás, alguns nem o são), mas buscam apresentar seu desenvolvimento histórico e diferentes formas de entendê-lo conforme autores significativos que se destacaram no estudo daquele tema. Assim, o dicionário, como, aliás, adverte sua organizadora, não reflete o pensamento de todos os autores, sendo

\footnotetext{
${ }^{2}$ Para Minayo (1999, p. 92) os conceitos "são as unidades de significação que definem a forma e o conteúdo de uma teoria". Já noção se refere às unidades de definição que intermediam experiência e conhecimento, mas não possuem, ainda, clareza ("qualidade de vida", por exemplo). As categorias, por outro lado, são os conceitos centrais de uma teoria, podendo ter um grau maior de abstração (categorias analíticas) ou maior relação com a especificidade da compreensão teórica da realidade (categorias empíricas a partir do ponto de vista do ser social). Portanto, noção, conceito e categoria distinguem termos teóricos em diferentes graus de maturação.
} 
difícil dar-lhe uma vertente unívoca. Porém sua coerência interna pode estar no fato de abrigar diferentes concepções, fugindo do dogmatismo, sem cair no ecletismo.

Por outro lado, se observados os verbetes adotados, estes são predominantemente pertencentes a categorias analíticas produzidas a partir das abordagens sociológica e histórica do objeto lazer. Essa escolha, consciente ou não, excluiu tanto conceitos ("atitude", “fluxo", "prazer") que mantém afinidade com a vertente psicológica do lazer quanto termos analíticos (“antilazer"; "semilazer") e empíricos ("ação comunitária") difundidos nos anos 1970 e 1980 e que, na atualidade, perderam prestígio nos meios acadêmico e profissional por serem considerados funcionalistas e esquemáticos.

As categorias empíricas, por sua vez, ocupam metade dos verbetes do dicionário. Sua maciça presença representa a própria condição histórica da área, muito ligada ao plano da ação. É louvável, portanto, perceber o esforço dos autores em lançar reflexão sobre diversos contextos da prática profissional (comunidade, poder público, mercado) os quais ainda são desprovidos de entendimento conceitual consistente. A aplicação desses verbetes será fecunda em pesquisas de campo e na prática profissional reflexiva.

Com isso, o dicionário será útil para diferentes tipos de leitores e necessidades. Todavia, não obstante a multiplicidade de olhares, garantida pela presença de diferentes autores e matrizes teóricas, a obra possui limites em sua abrangência/especificidade muito devido a não ter sido possível contemplar verbetes correntes ou emergentes na compreensão do lazer. ${ }^{3}$ Alguns deles, inclusive, estão discutidos noutros verbetes, mas a falta de um índice remissivo dificulta não somente essa consulta, mas, também, a integração sistêmica entre as noções, conceitos e categorias (empíricas e analíticas) do livro.

\footnotetext{
${ }^{3}$ Além dos já arrolados, se poderia acrescentar: cidade, clube, corpo, descanso, dinâmica de grupo, entretenimento, férias, folclore, hedonismo, leitura, ludoterapia, preguiça, recreador, simulacro, sinergia, tribos, turismo, vertentes funcionalistas do lazer, viagem, workaholic.
} 
Por fim, foi evitado um necessário diálogo com autores de língua espanhola no que concerne às diferenças conceituais sobre ócio, tempo livre, animação e recreação. ${ }^{4}$ No plano teórico, esse limite significativo do dicionário o enclausura, deixando de provocar debates fundamentais, senão à integração latinoamericana nos estudos do lazer, ao menos para explicitar as diferenças.

Porém, uma obra precisa ser principalmente analisada não pelo que poderia ou deveria (e, em edições atualizadas, ainda pode) vir a ser, mas tal como ela se apresenta. Até porque existem determinantes materiais na publicação de um livro que escapam ao tomo final idealizado pelos autores. Estes se propugnaram a missão de "problematizar aspectos essenciais para uma abordagem crítica sobre o lazer" (GOMES, 2004, p. 08), ansiando auxiliar o trabalho didático de estudantes e professores, além de enriquecer a compreensão da população em geral sobre a temática. E, neste sentido, foram bem sucedidos.

De fato, concordando com a recomendação dada por Ethel Bauzer Medeiros, na orelha do livro, o Dicionário Crítico do Lazer pode ser adotado como obra de referência para "especialistas e leigos na matéria". Se, em si, cada vocábulo apresenta uma 'cristalização' densa, a bibliografia ao final de cada termo instiga o leitor para aprofundamentos posteriores. Logo, assevera-se a indicação de Medeiros, dada a pluralidade de vocábulos, discutidos de forma fundamentada e didaticamente elaborados para fornecer ao leitor sínteses da produção intelectual nos estudos do lazer.

\section{Referências Bibliográficas}

BARBANTI, V. J. Dicionário de Educação Física e esporte. 2 ed. São Paulo: Manole, 2002.

BRAGA, R. Dicionário de turismo. Uniletras, 2003.

FANALI, Otávio Augusto A. C. Terminologia da educação fisica e desportos.

Brasília: Departamento de Documentação e Divulgação, 1981.

\footnotetext{
${ }^{4}$ Sempre vale recordar não existir a palavra lazer (do latim licere) no vocábulo espanhol. Portanto, ócio assume o significado de lazer para eles, mas mesmo tempo livre e recreação apresentam nuances importantes se comparados ao entendimento na língua portuguesa.
} 
GOMES, C. L (Org.). Dicionário crítico do lazer. Belo Horizonte: Autêntica, 2004.

GONZÁLEZ, F. J.; FENSTERSEIFER, P. E. (Org.). Dicionário crítico de Educação

Física. Ijuí: Ed. Unijuí, 2005.

MINAYO, C. O desafio do conhecimento. 6. ed. São Paulo: Hucitec, 1999.

OUTHWATTE, W.; BOTTOMORE, T. (Org.). Dicionário do pensamento social do

século XX. Rio de Janeiro: Zahar, 1996.

PELLEGRINI FILHO, A. Dicionário enciclopédico de ecologia e turismo. São Paulo:

Manole, 2000.

THINÉS, G.; LEMPEREUR, A. (Org.). Dicionário geral das ciências humanas.

Lisboa. Edições 70.

Resumo:

Ao analisar a obra Dicionário crítico do lazer, evidencia-se o rigor na clarificação dos vocábulos usados no campo lexical afeito ao lazer e à recreação, numa perspectiva crítica. Também são feitas considerações para o aperfeiçoamento de trabalhos dessa natureza.

Palavras-Chave: Lazer; Educação; Abordagem sociocultural.

\section{Abstract}

When analyzing the book Critical Dictionary of the Leisure, the watchfulness is evidenced in the each clarification of the lexicon used in leisure and recreation, in a critical perspective. They are also made considerations for the improvement of works of that nature.

Key-Words: Leisure; Education; Sociocultural research.

\section{SOBRE EL CAMPO LÉXICO DEL OCIO: RESEÑA DEL DICCIONARIO CRÍTICO DEL OCIO.}

Al analizar el libro Diccionario Crítico del Ocio, se evidencia el cuidado en cada clarificación de las palabras frecuentes en léxico del tiempo libre y recreación, en una perspectiva crítica. Otrosí son hechas consideraciones hecho por la mejora de trabajos de esa naturaleza.

Palabras-Claves: Tiempo libre; Educación; Investigación sociocultural. 